cases. Undoubtedly, therefore, the main factor contributing to the inferior quality of coronary arteriograms in the district general hospital was the imaging and recording equipment itself, which was unable to compete with the purpose built system in the catheter laboratory.

Thus quality of image is the main constraint on coronary arteriography using the conventional facilities of a radiology department in a district general hospital. As the new generation of digital imaging equipment becomes available coronary arteriography in district general hospitals may become a more realistic prospect. Digital subtraction techniques not only provide superior quality of image but also permit highly accurate automated quantification of coronary stenoses. ${ }^{89}$ Nevertheless, if this new technology is to extend to the role of district general hospital radiology departments it will need to provide images at least as good as those obtained in the catheterisation laboratories of cardiological centres. In this study conventional fluoroscopy with videotape recording failed that test and cannot therefore be recommended for coronary arteriography in the district general hospital.

1 Hillis WS, Jones CR, Been M, Campbell BC, Fulton WFM. Intracoronary thrombolytic therapy performed within a coronary care unit: one year's experience. Scoll Med f 1986;31:25-9.

2 Timmis AD, Griffin B, Crick JC, Sowton E. Anisoylated plasminogen streptokinase activator complex in acute myocardial infarction: a placebocontrolled arteriographic coronary recanalization study. $\mathcal{J} \mathrm{Am}$ Coll Cardiol 1987;10:205-10.

3 Stewart JT, Ward DE, Pumphrey CW, Redwood D. Cardiac catheterisation as an outpatient procedure. Br Med f 1989;298:1182.

4 Davis K, Kennedy JW, Kemp HG, Judkins MP, Gosselin AJ Killip T. Complications of coronary arteriography from the collaborative study of coronary artery surgery (CASS). Circulation 1979;59:1105-11.

5 Kennedy JW, Baxley WA, Bunnell IL, et al Mortality related to cardiac catheterization and angiography. Cathet Cardiovasc Diagn 1982;8:323-40. catheterization and angiography. Cathet Cardiovasc Diagn 1982;8:323-40.
Kennedy JW. Complications associated with cardiac catheterization and Kennedy JW. Complications associated with cardiac catheterization anc angiography. Cathet Cardiovasc Diagn 1982;8:5-11

7 O'Sullivan JJ, Crean P, Walsh M, et al. Cardiac catheterisation using 5-French catheters. Eur Hearl f 1989;10 (abstr suppl): 17

8 Mancini GBJ, Simon SB, McGillem MJ, LeFree MT, Friedman HZ, Voge RA. Automated quantitative coronary arteriography: morphologic and physiologic validation in vivo of a rapid digital angiographic method. Circulation 1987;75:452-60

9 Cusma JT, Toggart EJ, Folts JD, et al. Digital subtraction angiographic imaging of coronary flow reserve. Circulation 1987;75:461-72.

Accepted 15 7anuary 1990

\title{
Alcohol intake: a risk factor for psoriasis in young and middle aged men?
}

\author{
Kari Poikolainen, Timo Reunala, Jaakko Karvonen, Jorma Lauharanta, Päivi Kärkkäinen
}

\section{National Public Health} Institute, Mannerheimintie 166, 00300 Helsinki, Finland

Kari Poikolainen, MD, scientist

\section{Department of Dermatology, Tampere University Central Hospital, Ritakatu 1, 33520 Tampere, Finland Timo Reunala, $\mathrm{MD}$, associate professor \\ Department of Dermatology, Oulu University Central Hospital, Kajaanintie 52, 90220 Oulu, Finland Jaakko Karvonen, MD, associate professor}

\section{Department of} Dermatology, Helsinki University Central Hospital, Snellmaninkatu 14, 00170 Helsinki, Finland Jorma Lauharanta, $\mathrm{MD}$, senior dermatologist

Research Unit for Alcohol Diseases, University of Helsinki, Tukholmankatu 8F, 00290 Helsinki, Finland Päivi Kärkkäinen, LICMED, research assistant

Correspondence to: Dr Poikolainen.

\section{Abstract}

Objective - To clarify the nature of the association between alcohol intake and psoriasis.

Design-Case-control study of men aged 19-50 with onset of skin disease in $\mathbf{1 9 7 6}$ or later.

Setting-Outpatient clinics of the departments of dermatology of the university central hospitals in Helsinki, Oulu, and Tampere from September 1987 to April 1989.

Subjects-144 Patients with psoriasis and 285 unmatched controls with other skin diseases.

Main outcome measures-Results of clinical examination and self administered questionnaire assessing lifestyle and alcohol intake during two specified periods-namely, 12 months before the onset of skin disease and 12 months before the date of examination.

Results-Recalled mean alcohol intake before the onset of skin diseases was $42.9 \mathrm{~g} /$ day among the patients with psoriasis and $21.0 \mathrm{~g} /$ day among the controls. In logistic regression analysis psoriasis was associated with alcohol intake but not with coffee consumption, smoking, age, marital state, or social group. The odds ratio for psoriasis at an alcohol intake of $100 \mathrm{~g} /$ day compared with no intake was $2 \cdot 2$ (95\% confidence interval 1.3 to 3.9 ). The controls decreased their alcohol intake after the onset of the disease but the group with psoriasis did not. Analysis of serum enzyme values showed that $\gamma$-glutamyltransferase activity was significantly correlated with alcohol intake $(r=0.35)$, the mean activity being 75.0 U/1 among patients with psoriasis and $41.9 \mathrm{U} / 1$ among controls.

Conclusions - Alcohol is a risk factor for psoriasis in young and middle aged men, and psoriasis may sustain drinking.

\section{Introduction}

The relation between alcohol and psoriasis is controversial. Some studies suggest that psoriasis is more prevalent $^{1.3}$ and more severe ${ }^{45}$ among heavy drinkers whereas other studies have not found any association. ${ }^{6-11}$
The course of psoriasis is chronic. Skin manifestations may be severe and cause emotional problems, ${ }^{12}$ which themselves may lead to relief drinking. Our study aimed at clarifying whether psoriasis increases drinking, whether drinking increases the risk of psoriasis, and whether drinking worsens psoriasis.

\section{Patients and methods}

We studied consecutive male patients with psoriasis and male controls with other skin diseases admitted to the outpatient clinics of the departments of dermatology of the university central hospitals in Helsinki, Oulu, and 'Tampere from September 1987 to April 1989. We ignored whether patients were treated as outpatients or inpatients. To reduce errors in recall and reporting bias $^{13}$ we restricted the study group to patients aged 19-50 whose onset of skin disease was in 1976 or later. We aimed at collecting 50 patients with psoriasis and 100 controls in each centre. Six patients with psoriasis and two controls refused. One patient with psoriasis was too drunk to cooperate and five others gave no specific reason for refusal, and one control patient was too busy and another thought the questions too personal.

Of the 451 patients originally collected, 15 failed to meet the study criteria and six did not answer the question concerning the onset of their skin disease. Of the 15 patients who failed to meet the study criteria, eight were younger than 19 , two were over 50 , and five had had their skin disease since before 1976. One patient with psoriasis was excluded because his admitted alcohol intake of $28 \mathrm{~g}$ /day was incompatible with the clinical signs of intoxication and extremely high laboratory values (for example, $\gamma$-glutamyltransferase activity $1160 \mathrm{U} / \mathrm{l}$, mean corpuscular volume $104 \mathrm{fl}$ ). The final study group thus comprised 144 patients with psoriasis and 285 controls (table I).

\section{CHARACTERISTICS OF THE PATIENTS}

No significant differences were found between the patients with psoriasis and the controls with respect to age, marital state, and social class distribution. The 


\begin{tabular}{lr}
\hline & No of cases \\
\hline Types of psoriasis: & \\
Plaque & 127 \\
Guttate & 8 \\
Arthropathic & 7 \\
Pustular & 2 \\
\hline Total & 144 \\
\hline Diagnoses in controls: & \\
Dermatitis (atopic, contact, etc) & 113 \\
Skin infections & 28 \\
Acne and rosacea & 19 \\
Urticaria & 16 \\
Lichen ruber & 15 \\
Connective tissue diseases & 11 \\
Leg ulcers and vasculitis & 9 \\
Bullous diseases & 8 \\
Lichen simplex chronicus & 7 \\
Palmoplantar pustulosis & 6 \\
Miscellaneous skin diseases & 53 \\
\hline Total & 285 \\
\hline
\end{tabular}

mean age of the patients with psoriasis was $35 \cdot 0$ (SE $0.7)$ years and that of the controls $33.8(0.5)$ years $(\mathrm{p}=$ $0 \cdot 15)$. Of the 429 patients, $133(31 \%)$ were single, 226 $(53 \%)$ were in their first marriage, $27(6 \%)$ were in their second or subsequent marriage, $39(9 \%)$ were divorced, and $3(1 \%)$ were widowed (one response missing). The social class distribution (coding of the Central Office of Statistics, Helsinki) ${ }^{14}$ was as follows: class I (professionals, managers, higher administrative or clerical employees) 47 patients $(11 \%)$; class II (lower clerical employees) 81 patients (19\%); class III (skilled workers) 253 patients (59\%); class IV (unskilled workers) 48 patients ( $11 \%$ )

\section{MEASUREMENTS}

All patients were examined by a dermatologist and the diagnoses based on the clinical findings. The proportion of the skin surface area affected was classified as follows (values used in statistical analyses given in parentheses): below $5 \%(2 \cdot 5 \%) ; 5-10 \%(7 \cdot 5 \%)$; $11-25 \%(18 \cdot 5 \%) ; 26-50 \%(38 \cdot 5 \%)$; over $50 \%(70 \%)$.

Patients were asked to fill in a self administered questionnaire. Trained research nurses gave advice only if a question was not understood. The questionnaire was in two parts. In the first part the subjects were asked to think about the 12 months preceding the onset of the skin disease and answer questions pertaining to that period. In the second part the patients were asked to focus on the 12 months (or less in some incident cases) preceding the date of examination. Questions pertaining to food intake, coffee consumption, smoking, use of the sauna, and various life events were asked to prevent undue preoccupation with alcohol. For coffee intake and smoking the highest response alternatives were 10 cups or more and 60 cigarettes or more. Before the onset of the skin disease the mean number of cigarettes smoked was about 12 in both groups. The mean number of cups of coffee daily was $4 \cdot 3$ among the patients with psoriasis and 4.9 among the controls $(\mathrm{p}=0.04)$.

Alcohol intake was evaluated by a quantity-frequency type scale inquiring into the usual intake of beer, wine, and spirits. Based on previous research the questionnaire options were designed to enhance the reporting of frequent and heavy consumption. ${ }^{15}$ In calculating the average daily alcohol intake (grams of $100 \%$ ethanol) the following ethanol concentrations were used: beer and long drinks $40 \mathrm{~g} / \mathrm{l}$; natural wines $92 \mathrm{~g} / \mathrm{l}$; fortified wines $148 \mathrm{~g} / \mathrm{l}$; spirits $300 \mathrm{~g} / \mathrm{l}$. These figures were based on the average alcohol content of various beverages sold in Finland in 1987. The annual frequency of alcohol intoxication was ascertained by asking, "How often did you drink enough alcohol to make you feel inebriated, even if only slightly?"
To obtain an independent estimate of the accuracy of self reported alcohol intake serum $\gamma$-glutamyltransferase, aspartate aminotransferase, and $\beta$-hexosaminidase activities were ascertained in fasting blood from the Helsinki subsample. All samples were centrifuged and the serum kept frozen at $-20^{\circ} \mathrm{C}$ until analysed. $\gamma$-Glutamyltransferase and aspartate aminotransferase activities were measured by Reflotron (Boehringer Mannheim) at $37^{\circ} \mathrm{C}$. $\beta$-Hexosaminidase activity was determined spectrophotometrically by using $p$-nitrophenyl- $N$-acetyl- $\beta$-glucosamine (Sigma) as a substrate in citrate buffer at $\mathrm{pH} 4 \cdot 5.1617$

\section{STATISTICAL ANALYSIS}

The $t$ test was used to study differences in continuous variables between two groups and the $F$ test to study differences among multiple groups. Associations between categorical variables were studied by the $\chi^{2}$ contingency test (Yates's correction for $2 \times 2$ tables). Logarithmic transformations were used to reduce skewness before calculating linear correlation coefficients when appropriate. As some patients failed to answer certain questions the number of cases varied slightly depending on the variables under study. All non-responses were treated as missing values. Significance was taken as $\mathrm{p}<0 \cdot 05$. The program for generalised linear interactive modelling (GLIM) was used for fitting multiple logistic regression models. ${ }^{18}$ Odds ratios were estimated from the regression coefficients.

\section{Results}

ALCOHOL INTAKE DURING I 2 MONTHS BEFORE EXAMINATION

During the 12 months before examination the mean daily alcohol intake of the 129 patients with psoriasis for whom data were available was $44 \cdot 8$ (SE 7.8) g and that of the 238 controls $19.9(2 \cdot 1) \mathrm{g}(\mathrm{p}=0.002)$. The mean annual frequency of alcohol intoxication was 57.9 (SE 6.2) among 138 patients with psoriasis and $37 \cdot 2(2 \cdot 8)$ among 262 controls $(\mathrm{p}=0 \cdot 003)$.

In the Helsinki subsample, in whom serum enzyme activities were ascertained, alcohol intake correlated significantly with $\gamma$-glutamyltransferase activity $(\mathrm{r}=0.35 ; \mathrm{p}<0.001)$ and aspartate aminotransferase activity $(\mathrm{r}=0.30 ; \mathrm{p}<0.001)$ but not with $\beta$-hexosaminidase activity $(r=0 \cdot 12 ; p=0 \cdot 15)$. Activities of $\gamma$ glutamyltransferase and $\beta$-hexosaminidase were significantly higher among patients with psoriasis than among controls. Aspartate aminotransferase activity was also higher but the difference was not significant (table II)

TABLE II- $\gamma$-Glutamyltransferase, $\beta$-hexosaminidase, and aspartate aminotransferase activities (U/l) among patients with psoriasis and controls in Helsinki subsample

\begin{tabular}{|c|c|c|c|c|}
\hline & Mean & SE & No of cases & p Value ${ }^{\star}$ \\
\hline \multicolumn{5}{|c|}{$\gamma$-Glutamyltransferase activity: } \\
\hline Patients with psoriasis & $75 \cdot 0$ & $10 \cdot 8$ & $48 !$ & \multirow{2}{*}{0.007} \\
\hline Controls & $41 \cdot 9$ & $4 \cdot 8$ & 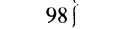 & \\
\hline \multicolumn{5}{|l|}{$\beta$-Hexosaminidase activity: } \\
\hline Patients with psoriasis & $25 \cdot 9$ & $1 \cdot 3$ & $48 !$ & \multirow{2}{*}{0.05} \\
\hline Controls & $22 \cdot 9$ & 0.8 & $98\}$ & \\
\hline \multicolumn{5}{|c|}{ Aspartate aminotransferase activity: } \\
\hline Patients with psoriasis & $29 \cdot 7$ & $3 \cdot 4$ & 49] & \multirow{2}{*}{$0 \cdot 14$} \\
\hline Controls & $24 \cdot 3$ & $1 \cdot 4$ & $98 j$ & \\
\hline
\end{tabular}

${ }^{\star}$ Two sided $t$ test; separate variance estimate.

\section{ALCOHOL INTAKE BEFORE ONSET OF SKIN DISEASE}

Before the first eruption of the skin disease the mean daily alcohol intake was $42.9 \mathrm{~g}$ among patients with psoriasis and $21.0 \mathrm{~g}$ among controls $(\mathrm{p}=0.004$; table III). The mean annual frequencies of intoxication in the two groups were $61 \cdot 6$ and $42 \cdot 6$ respectively $(\mathrm{p}=$ 
$0.007)$. A total of 13 of all 144 patients with psoriasis and 36 of the 284 controls declared that they were abstinent. This difference was not significant.

TABLE III - Alcohol intake ( $g /$ day) and frequency of intoxication (times/year) before onset of skin disease among patients with psoriasis and controls

\begin{tabular}{lcccc}
\hline & Mean & SE & No of cases & p Value \\
\hline Alcohol intake: & & & & \\
$\quad$ Patients with psoriasis & $42 \cdot 9$ & $7 \cdot 2$ & $142\}$ & 0.004 \\
$\quad$ Controls & $21 \cdot 0$ & $2 \cdot 1$ & $265\}$ & \\
$\begin{array}{l}\text { Frequency of intoxication: } \\
\quad \text { Patients with psoriasis }\end{array}$ & $61 \cdot 6$ & $6 \cdot 2$ & $131\}$ & 0.007 \\
$\quad$ Controls & $42 \cdot 6$ & $3 \cdot 3$ & $247\}$ & \\
\hline
\end{tabular}

^Two sided $t$ test; separate variance estimate.

Patients with psoriasis had had their skin disease for an average of 5.5 years and the controls their skin disease for an average of 3.3 years $(p<0.001)$. The duration of the skin disease did not correlate with the alcohol intake before onset $(r=0 \cdot 04)$.

To control for possible confounding factors logistic regression models were fitted to data pertaining to the 356 observations with no missing responses in any of the variables under study. Psoriasis was not associated with smoking, coffee intake, age, social class, or marital state. Omitting these variables did not worsen the model significantly. Alcohol intake and the frequency of intoxication were individually the only significant explaining variables. At an alcohol intake of $100 \mathrm{~g} /$ day compared with no intake the odds ratio for psoriasis was $2 \cdot 2(95 \%$ confidence interval $1 \cdot 3$ to $3 \cdot 9)$. For being intoxicated once a week compared with not at all the odds ratio was $1 \cdot 3(1 \cdot 1$ to $1 \cdot 5)$.

\section{CHANGE IN ALCOHOL INTAKE}

Comparison of the alcohol intake 12 months before the onset of the skin disease with that during the 12 months preceding the examination showed that in patients with psoriasis the mean intake had increased whereas in controls it had decreased. This difference between the groups was significant (table IV). The number of patients reporting alcohol intake during both periods was slightly smaller than the number reporting alcohol intake in one period only.

TABLE IV - Change in alcohol intake (g/day) from 12 months before onset of skin disease to 12 months before examination among patients with psoriasis and controls

\begin{tabular}{lcccc}
\hline & Mean & SE & No of cases & p Value \\
\hline Patients with psoriasis & +3.36 & 2.64 & 127 & \multirow{2}{*}{$\begin{array}{l}\text { (2. } \\
\text { Controls }\end{array}$} \\
\hline
\end{tabular}

*Two sided $t$ test; separate variance estimate.

\section{SEVERITY OF PSORIASIS AND ALCOHOL INTAKE}

Patients with psoriasis reported significantly more often $(p=0 \cdot 04)$ than controls that drinking seemed to worsen their skin disease. Worsening was reported by over a third of patients with psoriasis and roughly one in nine controls. There was no significant relation, however, between the extent of the body area affected and the average alcohol intake recalled during the 12 months preceding the examination among the patients with psoriasis, although those with larger areas of diseased skin tended to drink more (table V). A weak and non-significant trend also emerged when the frequency of intoxication was studied (data not shown). The correlation between the extent of the disease and alcohol intake was weak and non-significant $(r=0 \cdot 14)$, as was the coefficient between the extent of the disease and recent frequency of intoxication $(r=0 \cdot 07)$. No significant associations were found between alcohol intake and the duration of the skin disease or the
TABLE v-Percentage of body surface area affected with psoriasis and alcohol intake during 12 months preceding examination

\begin{tabular}{|c|c|c|c|}
\hline \multirow{2}{*}{$\begin{array}{c}\% \text { Of body surface } \\
\text { area affected }\end{array}$} & \multicolumn{2}{|c|}{ Alcohol intake (g/day) } & \multirow[b]{2}{*}{ No of cases } \\
\hline & Mean & SE & \\
\hline$<5$ & $37 \cdot 8$ & 8.4 & 51 \\
\hline $5-10$ & $41 \cdot 2$ & 8.6 & 31 \\
\hline $11-25$ & $49 \cdot 3$ & 20.9 & 28 \\
\hline $26-50$ & $24 \cdot 7$ & 9.8 & 11 \\
\hline$>50$ & $115 \cdot 6$ & $81 \cdot 2$ & 8 \\
\hline Total & $44 \cdot 8$ & $7 \cdot 8$ & 129 \\
\hline
\end{tabular}

number of visits to dermatologists during the preceding 12 months (data not shown).

\section{Discussion}

In this study alcohol intake was assessed during two specified periods - namely, 12 months before the onset of skin disease and 12 months before the date of examination. During both periods patients with psoriasis had a clearly higher self reported alcohol consumption than controls. That the mean intake of alcohol was high before the onset of psoriasis is a new finding and indicates that alcohol is a risk factor for the disease among young and middle aged men. Furthermore, that patients with psoriasis did not decrease their alcohol intake whereas controls did suggests that psoriasis may sustain drinking, possibly because of emotional distress. A decrease in alcohol intake would have been expected in both study groups given that intake tends to decrease with age. ${ }^{19}$

Self reported alcohol intake based on recall is almost always an underestimate, and underestimation may increase the further back the subject is asked to recall. In this series recalling alcohol intake 12 months before the onset of skin disease required casting the mind back one to 12 years. We tried to minimise underestimation by using a questionnaire designed to encourage reporting of high alcohol intake. Alcohol intake before the onset of the skin disease was not related to the duration of the disease, which speaks against increasing underestimation with time in our data. A recent study also suggests that the reliability of recalling alcohol intake some eight years before may be satisfactory. ${ }^{20}$ Further credibility is provided by our finding that self reported alcohol intake during the 12 months preceding the examination was in reasonable agreement with alcohol related laboratory results and by the consistency between the results based on alcohol intake and frequency of intoxication.

Heavy drinking increases the risk of infections and mechanical trauma, which are known to trigger psoriasis. ${ }^{21}$ Metabolic and immunological effects of alcohol may also contribute to the onset and flare ups of psoriasis. Psoriatic skin lesions typically show epidermal hyperproliferation and accumulation of polymorphonuclear leucocytes and mononuclear cells. Infiltrating cells are important in the initiation, maintenance, and resolution of psoriatic lesions. ${ }^{21}$ Both in vivo and in vitro evidence suggests that polymorphonuclear leucocyte chemotaxis correlates with the activity of psoriasis. ${ }^{21-23}$ Alcohol increases in vitro the chemotactic activity of polymorphonuclear leucocytes from patients with psoriasis but not those from controls, and this increase is most evident in patients whose psoriasis is exacerbated by alcohol ( $T$ Ternowitz, U Søderberg, paper presented to the 25th Nordic dermatological congress, Copenhagen, June 1989).

These findings indicate that alcohol is a risk factor for psoriasis in men and warrant further studies based only on incident cases. As psoriasis also seems to sustain drinking these patients should receive alcohol education and treatment. 
This study has been supported by a grant from the Finnish Foundation for Alcohol Studies.

1 Braathen LR, Botten (i, Bierkedal T Psoriatics in Norway: a questionnaire study on health status, contact with paramedical professions, and alcoho and tobacco consumption. Acta Derm Venereol (Stockh) 1989;suppl 142: and 9 -12.

Chaput J-C, Povnard T, Naveau S, Penso D, Durrmever O, Suplisson D. Psoriasis, alcohol, and liver disease. Br.Med f 1985;291:25.

3 Lindegard B. Diseases associated with psoriasis in a general population of 159200 middle-aged, urban, native Swedes. Dermatologica 1986;172 159200

+ Monk BE, Neill SM. Alcohol consumption and psoriasis. Dermatologica 1986;173:57-60.

5 Morse RM, Perry HO, Hurt RD, Alcoholism and psoriasis. Alcoholism 1985;9:396-9.

6 Baughman RD, Landeen RH, Maloney ME, Stern RS. Psoriasis and alcohol. In: Farber EM, Cox AJ, Nall L, Jacobs PH, eds. Psuriasis: proceedings of the third international symposium, Stanford Unizersity, 1981. New York: Grune and Stratton, 1982:323-4

7 Carmichael MM, Stankler L, White MI. Alcohol intake of patients with psoriasis and dermatitis. Health Bull (Edinb) 1984:42:258-62.

8 Delaney TJ, Leppard B. Alcohol intake and psoriasis. Acta Derm V'encreol (Stockh) 1974;54:237-8.

9 Grunnet E. Alcohol consumption in psoriasis. Dermatologica 1974;149:136-9.

10 Kavli G, Forde OH, Arnesen E, Stenvold SE. Psoriasis: familial pre disposition and environmental factors. Br Med f 1985;291:999-1000.

11 Rosset M, Oki G. Skin diseases in alcoholics. Quarterly fournal of Studies on Alcohol 1971;32:1017-24.

12 Ramsay B, O'Reagan M. A survey of the social and psrchological effects of psoriasis. Br f Dermatol 1988;118: 195-201.

13 Simpura J, Poikolainen K. Accuracy of retrospective measurement of individual alcohol consumption in men: a reinterview after 18 rears. I Stud Alcohol 1983;44:911-7.

14 Tilastollinen päätoimisto. Aakkosellinen ammattihakemisto. Vaestölaskenta 1970. Täydennetty painos. Helsinki: Tilastollinen paätoimisto, 1971. Central Office of Statistics. Alphabetical coding manual for social class hased on occupations. Population census 1970. Revised edition. Helsinki: Central Office of Statistics, 1971 .

15 Poikolainen K, Kärkkäinen P. Nature of questionnaire options affects estimates of alcohol intake. F Stud Alcohol 1985;46:219-22.

16 Levry GA, Conchie J. Mammalian glycosidases and their inhibition by aldonolactones. In: Neufeld EF, Ginsburg V, eds. Methods in enzymologv. Vol VIII. New York: Academic Press, 1966:571-84.

17 Pitkänen E, Kyllästinen M, Koivula T, Hormila P. Beta-N-glucosaminidase and beta-glucuronidase activities in insulin-dependent diabetic subjects and beta-glucuronidase activities in insulin-

18 Baker RJ, Nelder JA. The GLIM system, release 3. Oxford: Numerical Algorithms Group, 1978.

19 Simpura J, ed. Finnish drinking habits: results from interview surveys held in 1968 1976, and 1984. Vol 35. Helsinki: Finnish Foundation for Alcohol Studies, 1976 ,

20 Sobell LC, Sobell MB, Riley DM, et al. The reliability of alcohol abusers' selfreports on drinking and life events that occurred in distant past. I Siud Alcohol 1988;49:225-32

21 Christophers E, Krueger GG. Psoriasis. In: Fitzpatrick TB, Eisen AZ, Wolf $\mathrm{K}$, Freedberg IM, Austen KF, eds. Dermatology in general medicine. New York: Mc Graw-Hill, 1987:461-91.

22 Greaves MW. Neutrophil polymorphonuclears, mediators and the pathogenesis of psoriasis. Br f Dermatol 1983;109:115-8.

23 Sonnex TS, Carrington P, Norris P, Greaves MW. Polymorphonuclear leukocyte random migration and chemotaxis in psoriatic and healthy adult smokers and non-smokers. Br f Dermatol 1988;119:653-9.

Accepted 15 fanuary 1990)

\section{Association between parasuicide and Saint Valentine's Day}

\author{
Susan M Davenport, Jan Birtle
}

Correspondence to:

Dr Birtle.

BrMed f 1990;300:783-4

Experience in a casualty department suggested to us that an unusually high number of patients who had taken an overdose of drugs presented on Saint Valentine's Day (14 February). Previous studies have shown an association between parasuicide (non-fatal deliberate self harm) and stressful events such as an unsuccessful relationship, unemployment, and physical illness.' The festival of Saint Valentine's Day may induce stress due to unrequited love, but to our knowledge the incidence of parasuicide on this day has not been determined. We therefore investigated

\section{University Department of \\ Psychiatry, Queen \\ Elizabeth Hospital, \\ Birmingham B15 2TH \\ Susan M Davenport, BSC, medical student \\ Jan Birtle, MRCPSYCH, \\ lecturer in psychiatry} the association between Saint Valentine's Day and parasuicide.

\section{Patients, methods, and results}

We sought information on all patients presenting to one accident and emergency unit in each of the Central, South, and West Birmingham health districts on particular days during 1983-8. The days were Saint Valentine's Day; 7 February and 15 August (control days selected to minimise possible bias due to the season or day of the week); and Christmas Day, another festival traditionally linked with strong emotions. The number of cases of parasuicide was recorded for each day. The Poisson distribution was used to calculate $95 \%$ confidence intervals for the numbers of cases.

One hundred and seventy cases of parasuicide were seen. More cases occurred on Saint Valentine's Day than on the two control days or Christmas Day (table).

Number of cases of parasuicide (number in which patient was adolescent) seen at three casualty department on Saint Valentine's Day, Christmas Day, and two control days, 1983-8

\begin{tabular}{|c|c|c|c|c|c|c|c|c|}
\hline & 1983 & 1984 & 1985 & 1986 & 1987 & 1988 & Total & $\begin{array}{l}95 \% \text { Confidence interval } \\
\text { of No of cases }\end{array}$ \\
\hline Saint Valentine's Day & $11(3)$ & $11(5)$ & $10(6)$ & $10(4)$ & $11(5)$ & $16(8)$ & $69(31)$ & $53 \cdot 7$ to $83 \cdot 3(21 \cdot 1$ to $44 \cdot 0)$ \\
\hline Christmas Day & $9(3)$ & $6(2)$ & $8(3)$ & $8(2)$ & $8(3)$ & $6(3)$ & $45(16)$ & 32.8 to $60.2(9 \cdot 1$ to 26.0$)$ \\
\hline 7 February & $3(0)$ & $6(0)$ & $3(1)$ & $7(1)$ & $5(2)$ & $5(1)$ & $29(5)$ & 19.4 to $41.6 \quad(1.6$ to 11.7$)$ \\
\hline 15 August & $4(1)$ & $3(0)$ & $6(0)$ & $5(1)$ & 311 & $6(0)$ & 27 (3) & 17.8 to $39.3 \quad 0.6$ to 8.8$)$ \\
\hline
\end{tabular}

The $95 \%$ confidence intervals for the numbers of cases indicated an association with Saint Valentine's Day and, to a lesser extent, with Christmas Day.

Significant differences in age were found among the patients according to the day of presentation: those who presented on Saint Valentine's Day and Christmas Day (median age 21 and 22 respectively) were younger than those who presented on the control days ( 7 February, age 28; 15 August, age 31$)(p<0 \cdot 01$, Kruskal-Wallis non-parametric analysis of variance).

The proportion of patients who were adolescent (defined as those aged 12-20') was higher on Saint Valentine's Day (45\%) and Christmas Day (36\%) than on the control days (7 February, 17\%; 15 August, $11 \%)$. The $95 \%$ confidence intervals for the numbers of adolescent patients again indicated an association with Saint Valentine's Day and, to a lesser extent, Christmas Day (table).

\section{Comment}

Our study showed an association between Saint Valentine's Day and parasuicide, particularly in adolescent patients. There was also an association, although weaker, between parasuicide and Christmas Day.

We studied only people who attended hospital, so our figures are underestimates of the true incidence, although they probably reflect trends in the population. Case records were not detailed enough to confirm a causal association between disappointments in personal relationships and parasuicide, but our clinical experience suggests that such an association exists. In one series of adolescent self poisoners $52 \%$ reported difficulties in relationships with boyfriends or girlfriends, " which supports the possibility of a causal link. The suggestive association between Christmas Day and parasuicide is further evidence that festivals, and the consequent pressure on interpersonal relationships, may be of aetiological importance.

The dangers of parasuicide include physical damage, repetitive self injury, and death. ${ }^{+}$Information about aetiological factors can be useful in planning preventive strategies - for example, the provision of education and counselling for target groups. We suggest that those in contact with adolescents should be particularly vigilant during emotionally charged festivals such as Christmas Day and Saint Valentine's Day. 